\title{
A INAUGURAÇÃo do EDIFÍCIO de APOIO DA FACULDADE DE DIREITO
}

Em 11 de maio de 1994, às 9 horas, o Diretor da Faculdade de Direito da USP, Professor Doutor Antonio Junqueira de Azevedo, iniciou as cerimônias de inauguração do prédio anexo, construído no terreno que servia de estacionamento à Unidade, localizado na esquina da Avenida Brigadeiro Luís Antonio e Rua Riachuelo.

$\mathrm{Na}$ abertura das comemorações, foi realizada, no novo auditório, pelo Padre Paulo Pedreira de Freitas S.J., missa em ação de graças com a presença do Excelentíssimo Senhor Secretário da Justiça e Defesa da Cidadania, Doutor Antonio de Souza Corrêa Meyer, do Magnífico Reitor, Professor Doutor Flávio Fava de Moraes, da Vice-Reitora, Professora Doutora Myriam Krasilchik, do PróReitor de Graduação, Professor Doutor Carlos Alberto Barbosa Dantas, do Senhor Prefeito da Cidade Universitária, Professor Doutor Antonio Rodrigues Martins, dos Professores Eméritos da Faculdade de Direito da USP, Doutores Goffredo da Silva Telles Júnior e Philomeno Joaquim da Costa, demais professores, alunos e funcionários da Escola de Direito, recepcionados na honrosa missão pelo Senhor Diretor.

O novo prédio-de-apoio possui três andares intermediários, onde se distribuem seções administrativas e salas de aula para seminários e círculos de estudos, acrescido de dez andares para departamentos, além de garagem nos subsolos. Está ligado por uma passarela, no segundo andar, ao prédio da velha e sempre nova Academia. Após a missa, houve o descerramento da placa inaugural, localizada na entrada que dá acesso à Rua Riachuelo e, para terminar, por conta do Diretor, serviu-se aos presentes vinho branco e salgadinhos.

É o seguinte o texto da homilia lida pelo Padre Paulo Pedreira de Freitas, com bênção dada à Faculdade:

"A presença do sacerdote e o rito sacro da bênção litúrgica por ocasião da inauguração do novo prédio da Faculdade de Direito da Universidade de São Paulo vêm lembrar a presehça e a ação de Deus, Criador e Senhor, chancelando o passado eloqüente desta instituição e garantindo seu futuro ainda mais promissor. 
O Sacerdócio e os Ritos Litúrgicos da Igreja Católica, por vocação e instituição, são sinais eficazes da presença de Deus-Pai, fonte de vida e de bens, gratuita e misericordiamente atuando em favor dos seres humanos, chamados por Ele à existência para participarem, livre e amorosamente, de sua vida e, inclusive, do seu projeto criador.

$O$ sacerdote e o rito sacro nesta inauguração sinalizam uma presença e atuação sempre existentes, embora muitas vezes não percebidas conscientemente, pelo menos com denominação explicita uniforme.

Quero dizer que em toda a atuação desta memorável instituição, Faculdade de Direito da Universidade de São Paulo, através de seus eméritos diretores, professores e funcionários, como também através de seus alunos, a favor do desenvolvimento e do exercício da Ordem Jurídica, sustentáculo da dignidade e da convivencia humana, a presença de um Deus Criador e Senhor, embora oculta, inspirava e sustentava beneméritos esforços.

$O$ Deus, Criador e Senhor, esteve sempre presente acolhendo $e$ secundando as descobertas humanas. Fosse Ele invocado explicitamente, sob diversas denominações é discretamente percebido como verdade, justiça, viabilidade, amor e convivência. Havia sempre uma presença maior inspirando, unificando, chancelando todos os esforços realmente construtivos em vista de um imprescindivel serviço ao homem em todo o seu contexto pessoal e social.

$O$ único e grande interesse de Deus, Criador e Senhor, criando $e$ restaurando todo o Universo é sempre o homem, chamado a participar da própria vida divina, através de maravilhosa e gratuita integração ao próprio Filho de Deus, que nos busca, por mais longe que nos encontremos, através de sua Encarnação na História dos Homens.

Creio que não me engano se digo que o grande objetivo do Direito é, por uma parte, colocar todas as coisas ao serviço do homem, e, por outra, promover o adequado relacionamento e respeito entre as pessoas humanas.

$O$ fundamento último do Direito, aonde todos nós poderemos nos encontrar, mesmo na diversidade de raças, religiões ou etnias, se encontra na descoberta e explicitação das pegadas originais do Criador que dão consistência real ao relacionamento das coisas e das instituições com o homem e dos homens entre si. 
A busca de inspiração nas fontes genuinas de Deus-Pai, Criador $e$ Senhor, exclui toda tentativa arbitrária e presunçosa de construir um Direito sem Deus que, com o tempo, se mostraria quimérico, formalista e, até mesmo, idolátrico.

Não é isso que a parte mais sã da juventude que bate as portas de nossa Faculdade deseja!!! Estes jovens respondendo aos anseios da sociedade, da qual são deputados e orgulhosos representantes, desejam proporcionar a esta mesma sociedade, através do Direito ao alcance de todos, um instrumento ágil e eficaz, promissor e dinâmico que a ajude a desfrutar harmonicamente os bens existentes no planeta, incentivando o seu desenvolvimento, privilegiando a pessoa humana e garantindo o justo relacionamento entre toda a comunidade humana.

Certamente este fundamento último, estas pegadas do Deus Criador e Senhor, não será, sempre e imediatamente, detectado e interpretado. Será necessário compor e instaurar ensaios, tentativas provisórias e urgentes, sempre possiveis de aperfeiçoamento.

A generosidade do bom Deus nos proporcionando novos recursos, através das novas instalações desta Faculdade, é um estímulo para nossos eminentes mestres e esperançosa juventude. Os avanços tecnológicos atuais, sobretudo no campo da eletrônica, estimulam e viabilizam os mais ousados projetos. Os meios estão ai, cada vez mais, à nossa disposição. Os monstros ameaçadores e paralisantes dos limites operacionais estão sendo removidos. É pois cada vez maior a nossa responsabilidade. Nossa, dos homens que vamos inaugurar o terceiro milênio da Era Cristã da Humanidade. Nossa, de pessoas que detêm a capacidade de tornar a sociedade cada vez mais vióvel.

O novo edificio, além de tudo o que ele oferece diretamente como disponibilidade para o desenvolvimento do Direito, é também um marco, um símbolo, uma bandeira que lembra a todos os freqüentadores destas Arcadas a responsabilidade de, no ritmo do tempo atual, proporcionar à sociedade de hoje, por graças de Deus, sempre mais democrática, o instrumento jurídico que ela deseja e necessita.

Que esta bênção do nosso Deus, que é Pai e Baluarte da dignidade e liberdade humanas, seja uma expressão de louvor e de agradecimento ao muito que já foi feito por esta Faculdade a favor do ser humano, objeto prioritário do Amor Divino, e seja também garantia e penhor de futuras realizações, neste 
momento feliz da História, caracterizado pela crescente descoberta e valorização da Ordem Jurídica.

\section{Oremos.}

Abençoai, Deus Eterno, Todo-Poderoso e Amigo dos homens, este novo edifício da Faculdade de Direito do Largo de São Francisco, da Universidade de São Paulo, com todas as bênçãos de agradecimento, de louvor, de respeito e de encômios de tudo o que foi realizado por esta Faculdade para o bem da convivência humana nesta cidade de São Paulo, no Brasil e em todo o mundo. Igualmente abençoai, Senhor Deus, este novo edificio, seus equipamentos e sobretudo todos os seus freqüentadores, com todas as bênçãos da verdade, da fortaleza e da intuição do fundamental direito da pessoa humana, a fim de que esta Faculdade, usufruindo de todos os meios que a sociedade atual sabiamente the proporciona, possa egregiamente responder às promissoras esperanças $e$ responsabilidades de que é depositária. Formulamos, Deus Onipotente, este pedido de bênçãos, cheio de esperanças, interpretando a profunda e autêntica inspiração de todos os presentes. Que Jesus Cristo, o Senhor enviado pelo Pai, empenhado na restauração pacífica de toda ordem, e Maria, a Mãe de todos os homens, sejam, Pai Celeste, os nossos maiores intercessores.

Assim seja!" 


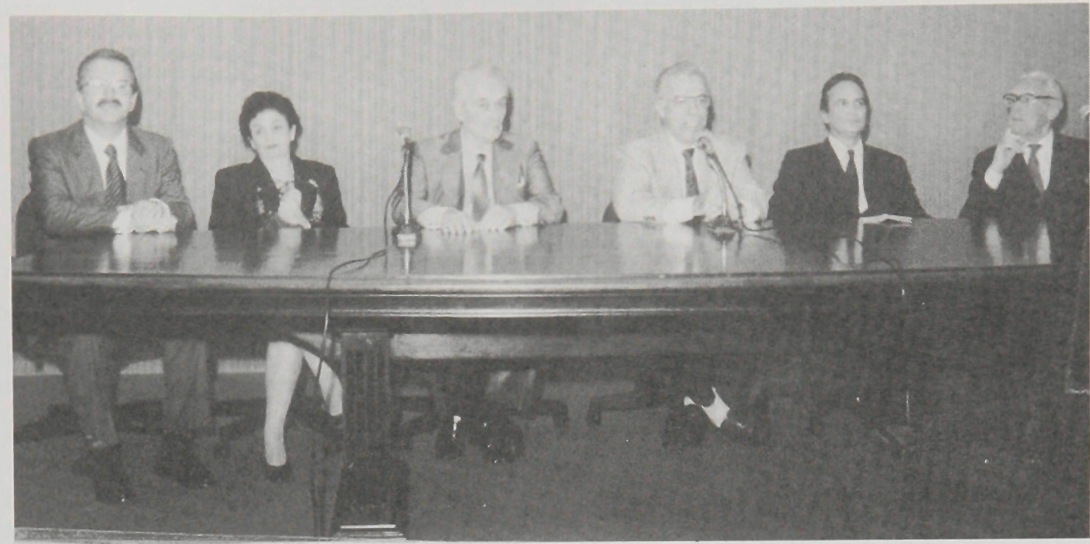

Dr. Antonio de Souza Corrêa Meyer, professores Myriam Krasilchik, Goffredo Silva Telles, Flávio Fava de Moraes, Antonio Junqueira de Azevedo e Philomeno Joaquim da Costa *

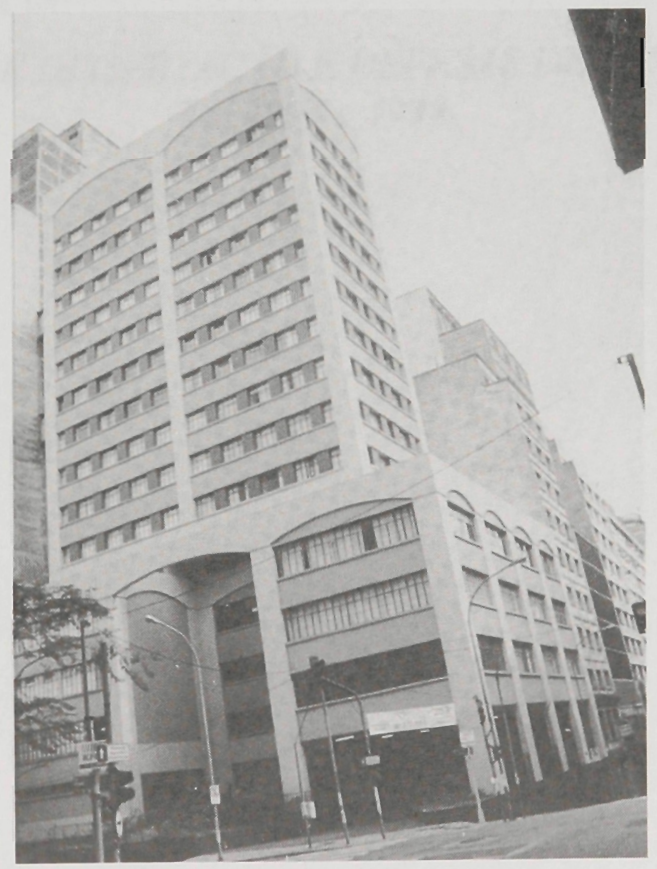

O novo prédio da Faculdade de Direito 